\title{
VIOLA BRASILEIRA, QUAL DELAS?
}

\section{BRAZILIAN VIOLA, WHICH ONE?}

\author{
André Moraes \\ Universidade de São Paulo \\ andrem934@gmail.com
}

\section{Resumo}

No Brasil existem diversos instrumentos de cordas dedilhadas que são denominados viola, muitas vezes referindo-se ao mesmo instrumento, porém com nomes diferentes: viola caipira, viola sertaneja, viola cabocla, viola nordestina, viola de festa, viola de feira, viola de fandango, viola de folia, viola de dez cordas, viola brasileira. Para uma possivel classificação hierárquica dos termos e dos instrumentos, buscamos a contribuição do campo da ciência da informação, sobretudo a terminologia. $\bigcirc$ estudo da ciência da informação nos revelou diversas possibilidades de representação e organização para um determinado domínio. Optamos neste caso por classificar o termo viola brasileira (termo genérico TG) e seus (termos específicos TE) viola de cocho, viola nordestina, viola de arame, viola de buriti, viola caiçara utilizando o conceito da terminologia e documentação analisado por Maria Teresa Cabré e Lídia Almeida Barros.

Palavra-chave: terminologia; ciência da informação; organização do conhecimento; viola; viola caipira; viola brasileira.

\section{Abstract}

In Brazil there are several strumming instruments that are called viola, often referring to the same instrument, but with different names: country guitar, country guitar, cabocla guitar, northeastern guitar, party guitar, fair guitar, Fandango Viola, Folio Viola, Ten String Viola, Brazilian Viola. For a possible hierarchical classification of terms and instruments, we seek the contribution of the field of information science, especially the terminology. The study of information science has revealed to us several 
possibilities of representation and organization for a given domain. In this case we chose to classify the Brazilian viola (generic term TG) and its (TE specific terms) trough viola, northeastern viola, wire viola, buriti viola, caiçara viola using the concept of terminology and documentation analyzed by Maria Teresa Cabré and Lidia Almeida Barros.

Keywords: terminology; information Science; knowledge organization; viola; country viola; Brazilian viola.

\section{Introdução}

A viola popular e tradicional do Brasil, identificada, dependendo da localidade, como viola caipira, também conhecida como viola sertaneja, viola cabocla, viola de arame, viola de dez cordas, viola nordestina, viola de repente, viola machete, viola caiçara, viola de feira ou viola brasileira', tem origem nas violas portuguesas, instrumento da família dos cordofones com cinco ordens de cordas duplas². Introduzida no Brasil por meio das missões Jesuítas, a viola caipira foi de grande uso no fazer musical do Brasil colonial e aos poucos foi deslocando-se do espaço urbano, limitando-se ao povo interiorano. Com isso o instrumento ganhou afinações, ritmos, modos e características particulares de cada região do país, transformando-se em um símbolo regional (PETENÁ, 2017 p. 7).

$\bigcirc$ presente trabalho com o tema "viola brasileira, qual delas?", discorre sobre a viola da familia de cordas dedilhadas e suas características versus questões terminológicas. Existem outros instrumentos

\footnotetext{
I "Definição encontrada na gravação do LP "Viola Brasileira", Sete Prelúdios e o Concertino de Ascendino Theodoro Nogueira tendo como solista o violonista Antônio Carlos Barbosa Lima, pela gravadora Chantecler 1963. Embora Nogueira tenha escrito que "Sendo o instrumento predileto do nosso caipira ou sertanejo, batizei-a com o nome de viola brasileira" (1963), chamar a viola de "brasileira" e não "caipira" no título da obra foi também uma escolha visando a maior aceitação da crítica e apreciadores do gênero clássico. Sugestão feita por Biaggio Baccarin (diretor artístico da gravadora Chantecler na época em que as obras foram lançadas) e aceita de imediato por Ascendino. De qualquer forma, para nenhuma distorção de identidade, na contracapa do disco o folclorista Rossini Tavares de Lima utiliza os dois termos: Viola Brasileira ou Caipira" (PETENÁ, 2017 pp. 13-16).

2 A viola pode ter cordas simples, duplas ou triplas, mas existem também as de 12 cordas, em seis pares e também com cinco ordens, com cordas triplas, como a da Profa. Gisela Nogueira.
} 
que recebem o nome de viola de outras familias, mas trataremos neste artigo somente das violas brasileiras.

Termo viola brasileira tem sido muito utilizado pelos compositores e instrumentistas em substituição ao termo viola caipira. Como cita Roberto Corrêa, isso gera um problema de classificação e organização desses instrumentos, pois a viola caipira tem características físicas, linguagens, contexto social e geográfico diferente de outras violas que existem pelo Brasil.

Desta forma, podemos chamar de viola brasileira a viola caipira? E as demais violas, como a viola de buriti, de cocho, caiçara, machete, cabaça, não são brasileiras? Em conversa com alguns compositores e violeiros, a justificativa por essa substituição seria pelo aumento da utilização da viola caipira em diversos gêneros musicais, não se restringindo somente a música caipira. Isso porque o termo "viola caipira" limitaria ou sugereria que o instrumento seria capaz somente de produzir música dentro deste segmento, o que não corresponde a realidade. Com a expansão técnica e interpretativa que a viola alcançou nas últimas décadas, o termo "viola caipira", na opinião desses violeiros, deixou de ter uma correspondência com o produto musical que sugere a denominação.

Dividiremos este artigo em duas partes. Num primeiro momento abordaremos questões históricas no entorno da viola e suas variantes elucidando suas características e pontos em comum das violas portuguesas e brasileiras. Posteriormente, sobre a questão terminológica, tendo como suporte as análises da Maria Tersa Cabré e Lídia Barros, utilizaremos os critérios da ciência da informação para elucidar, organizar e classificar os termos com o objetivo de facilitar a comunicação e disseminação do conhecimento. 


\section{Breve histórico da viola}

A viola que conhecemos hoje descende das violas portuguesas. Para o pesquisador Ivan Vilela (2011) a influência dos árabes teve grande importância na proliferação dos cordofones da península ibérica.

Quando os árabes chegaram à Península lbérica, no ano de 722, os instrumentos de cordas dedilhadas presentes na Península eram as harpas celtas e as cítaras grecoromanas. $\bigcirc$ oud, também conhecido por alaúde árabe, foi o primeiro instrumento de cordas dedilhadas com braço onde as notas podiam ser modificadas, que chegou à Europa. Curioso observarmos que a viola mantém como característica básica de seu velho ancestral as cinco ordens de cordas. $\bigcirc$ alaúde árabe tem cinco pares uníssonos e às vezes um bordão só é colocado abaixo das cordas mais agudas para facilitar as respostas entre graves e agudos na melodia. Muitas vezes este bordão é utilizado como um pedal. Normalmente este bordão solo tem a mesma nota que os bordões em dupla. Já a viola, independentemente do número de cordas que venha a possuir, de cinco a quinze, sempre mantém a ideia das cinco ordens, podendo ser estas simples, duplas, triplas ou até mistas. A partir do enlace cultural de mouros, cristãos e judeus sefarditas inúmeros instrumentos foram gestados. A fusão que se processou neste periodo na Península lbérica foi tal que por volta do século XIII, surgiu a guitarra latina. (VILELA, 2011, p. 116).

A península ibérica possuía uma grande diversidade de instrumentos de cordas dedilhadas. Em Portugal a viola já estava bem difundida em todo o território. Cada região criou sua própria viola, sendo possivel observar essas características na configuração do instrumento, no tamanho e no número de cordas. 


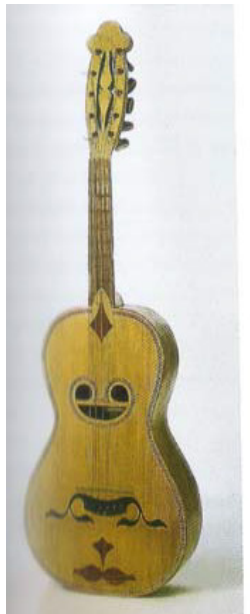

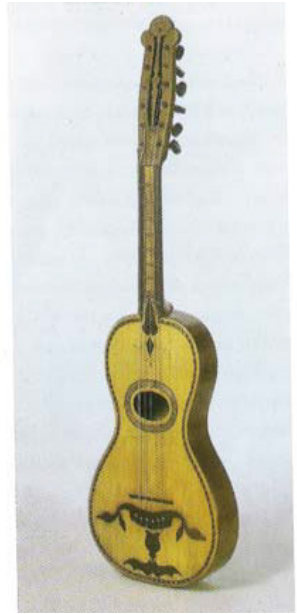

Três Violas Braguesas

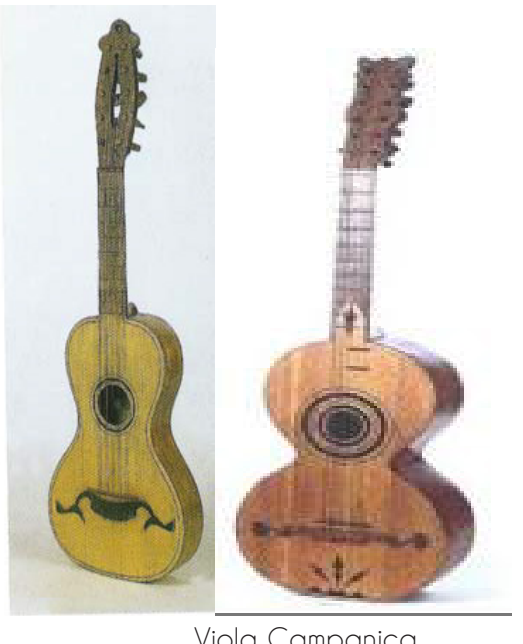

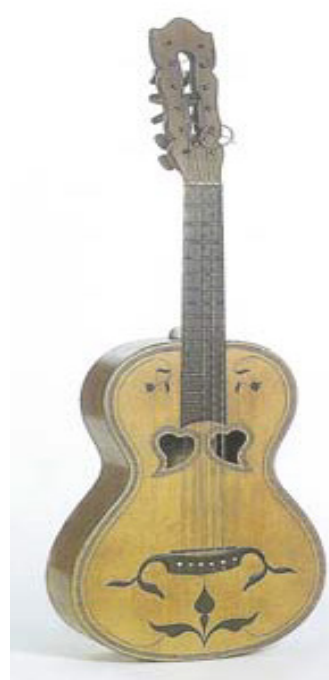

Viola Amarantina

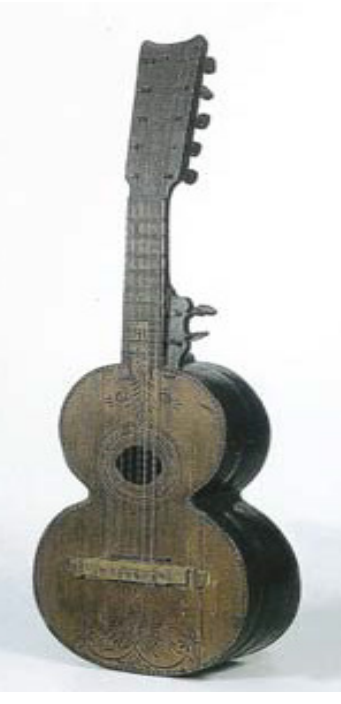

Viola de Beiroa

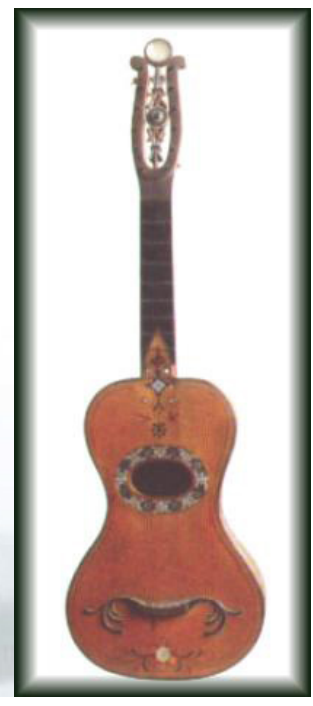

Viola Toeira

No norte a viola braguesa, no nordeste a viola amarantina ou de dois corações, no centro a viola beiroa, mais abaixo, próximo a Lisboa, a viola toeira e mais ao sul, no Alentejo, a viola campaniça. Elas variavam no tamanho, na forma $e$ no número de cordas, mas, na maioria das vezes, mantinham

\section{3}


uma característica comum: ter cinco ordens de cordas. $\bigcirc$ ukelele havaiano é uma transfiguração do cavaquinho como o rajão da llha da Madeira. Açores, Madeira e Cabo Verde têm suas próprias violas. (VILELA, 2011, p. 118).

Das cinco violas citadas acima apenas a Amarantina e a Campaniça não se fixaram no Brasil. A viola beiroa ainda mantém sua linhagem no litoral sul de São Paulo e no norte do Paraná onde são chamadas de viola fandangueira, e em São Paulo na região de lguape, de viola branca. (VILELA, 201 1, p. 119).

Os modelos antigos de viola de Queluz são fabricados artesanalmente na cidade de Conselheiro Lafaiete (MG). Esse modelo utiliza doze cordas mantendo as cinco ordens, ou seja, as três primeiras de baixo para cima duplas e as duas últimas ordens triplas com duas cordas finas de mesmo calibre, semelhante a viola toeira de Coimbra, Portugal. (VILELA, 2011, p. 120).

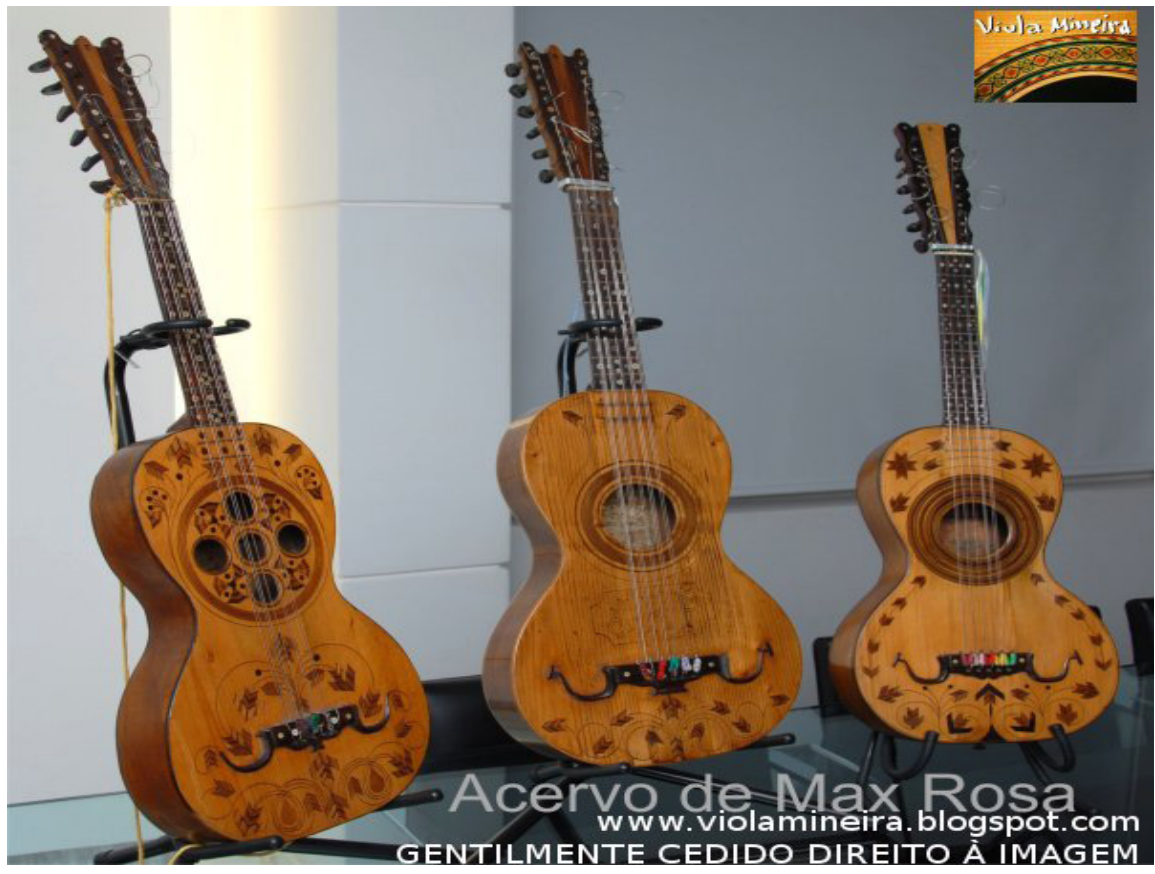




\section{Violas Brasileiras}

A viola caipira é um instrumento que tem suas raízes no contexto rural brasileiro. Desta forma, recebeu alguns nomes de acordo com a sua região. Segundo Ivan Vilela (2011) em sua tese de doutorado, as denominações da viola são: "viola caipira, viola sertaneja, viola de dez cordas, viola cabocla, viola de arame, viola de folia, viola nordestina, viola de repente, viola de festa, viola de feira, viola brasileira" (VILELA, 2011, p. 113). O autor ainda ressalta que este instrumento sempre esteve presente em várias manifestações culturais, com variedades de ponteados e ritmos que foram criados por violeiros, por meio de um "processo de hibridização" (ibidem).

Para o pesquisador Roberto Corrêa, a viola caipira, além dessas denominações já citadas, possui algumas particularidades com relação a encordoamento e afinações.

Viola caipira instrumento encontrado na região de influência histórica paulista, a região caipira do Brasil que, na delimitação do sociólogo Antônio Cândido, abrange uma grande área do Brasil Central. A viola caipira possui cinco ordens de cordas metálicas, sendo dois pares de cordas lisas de aço, afinados em uníssono, e três pares de cordas afinados em oitavas, ou seja, três bordões encapados com espiras de zinco ou bronze acompanhados, cada qual, por uma corda lisa de aço em intervalo de oitava. A afinação adotada pela maioria dos violeiros desta região é a Cebolão, que pode ser utilizada em diversas tonalidades, principalmente nas tonalidades de Ré ou Mi. No caso da Cebolão em Ré, de cima para baixo, com a viola na posição de tocar temos a seguinte disposição intervalar: [A2-A1, D3-D2, F\#3-F\#2, A2-A2, D3-D3]. Como se pode observar é uma afinação reentrante, ou seja, a nota mais aguda [F\#3] se encontra no terceiro par e não na prima, como na maioria dos instrumentos de cordas cuja disposição de cordas vai do grave para o agudo. Outras afinações também são utilizadas na viola caipira:

Natural [A2-A1, D3-D2, C3-C2, B2-B2, E3-E3];

Boiadeira [C2-C1, D3-D2, F\#3-F\#2, A2-A2, D3-D3];

Rio-Abaixo [C2-C1, D3-D2, G3-C2, B2-B2, D3-D3];

Meia-guitarra [C2-C1, C3-C2, C3-C2, B2-B2, D3-D3] (FUNARTE, 2019. p. 10). 

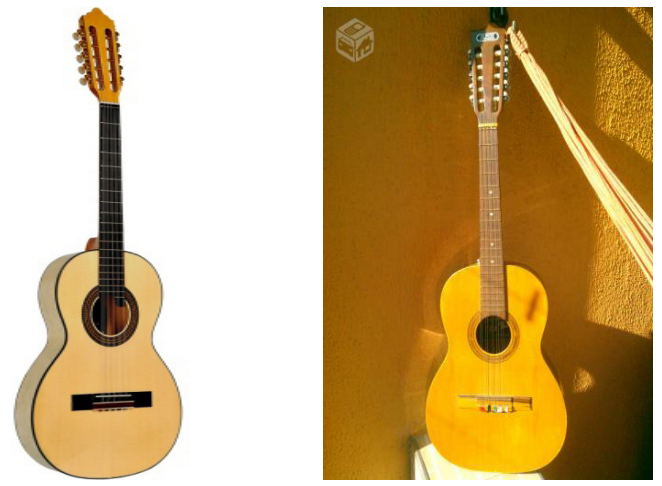

Violas caipiras

\section{Viola Dinâmica}

A viola que podemos encontrar no nordeste do Brasil é a viola dinâmica, muito utilizada para acompanhar o desafio de versos dos repentistas. (VILELA, 201 l).

No nordeste os repentistas se utilizam da viola dinâmica, um modelo criado no Brasil que tem amplificadores naturais feitos com cones de alumínio e, com isso, o timbre levemente modificado. Estas violas normalmente são encontradas com doze cordas distribuídas em cinco ordens, três pares e duas triplas. (VILELA, 2011, p. 120).

Corrêa apresenta demais características físicas da viola nordestina, a saber: afinações, diversas maneiras de encordoa-las e o modo pelo qual os repentistas a denominam.

A viola nordestina com cinco ordens duplas [A2-A 1, D3-D2, G3-G2, B2-B2, E3-E3], pouco se difere da viola caipira, a não ser por sua afinação característica, também reentrante [C3], pelo modelo de instrumento utilizado mais comumente a viola dinâmica, e pelo tipo de música que se faz com o instrumento. Viola-de-cantoria. No Nordeste, a viola de cordas dedilhadas, usada pelos cantadores repentistas, denominada viola-de-cantoria, apresenta-se com sete

\section{6}

REV. TULHA, RIBEIRÃO PRETO, v. 6, n. 1, pp. 9-35, jan.-jun. 2020 
cordas distribuídas em cinco ordens de cordas metálicas, sendo a quinta ordem tripla e as demais singelas (simples). Esta ordem tripla apresenta três cordas de calibragens diferentes, a saber: um bordão com corda encapada, a oitava do bordão, também com corda encapada, e a oitava da oitava do bordão, sendo esta uma corda lisa de aço. $\bigcirc$ modelo de instrumento mais utilizado pelos repentistas apresenta acessórios que the conferem um timbre peculiar, o instrumento possui um disco de metal, na parte interna, bem no centro do bojo maior do tampo. A vibração da corda é transmitida para uma peça de madeira circular e desta para um disco de alumínio em forma de cone cuja base está em contato com o disco de madeira (FUNARTE, 2019, p. 12).

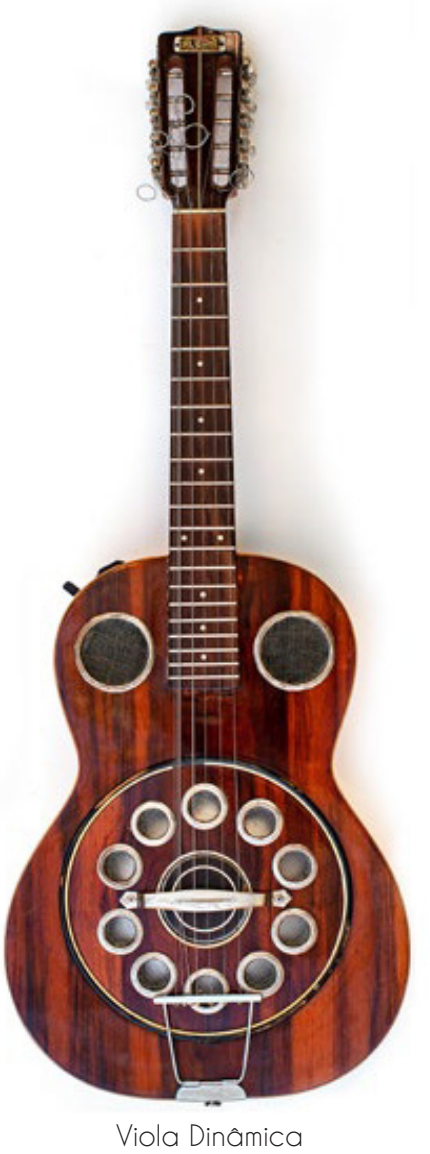

17 


\section{Viola de Cocho}

Podemos dizer que esta viola nasceu no Brasil. A viola de cocho é construída a partir de uma tora de madeira escavada no formato de um recipiente parecido com uma cuia grande para alimentar o gado com ração e sal. (CORRÊA, 2002, p. 56).

Viola-de-cocho Instrumento encontrado em alguns municípios dos estados de Mato Grosso e de Mato Grosso do Sul, esculpido em uma tora de madeira e escavado na parte que forma a caixa de ressonância. $\bigcirc$ instrumento apresentasse com cinco ordens de cordas singelas. A maioria das violas-de-cocho arma-se com quatro cordas de náilon (ou de tripa) e uma de aço encapada. A corda de aço recebe o nome de Canotio, e tem, aproximadamente, o mesmo calibre da quarta corda do violão. $\bigcirc$ número de pontos, ou trastes, varia entre dois e três. Quando a viola possui três pontos, o intervalo entre eles é de semitom; quando possui dois pontos, o primeiro dá o intervalo de um tom, e o segundo, de semitom. Os pontos são feitos de barbantes revestidos com cera de abelha para se grudarem à madeira do braço do instrumento. A viola-decocho possui duas afinações básicas, também reentrantes: Canotio Solto [C2, D2, E2, A2, D3] Canotio Preso [C2, C2, E2, A2, D3]. Suas dimensões são, aproximadamente: $70 \mathrm{~cm}$ de comprimento, $25 \mathrm{~cm}$ de largura do bojo inferior, $11 \mathrm{~cm}$ no bojo superior e $12 \mathrm{~cm}$ de espessura. (CORRÊA, 2002, p. 56).

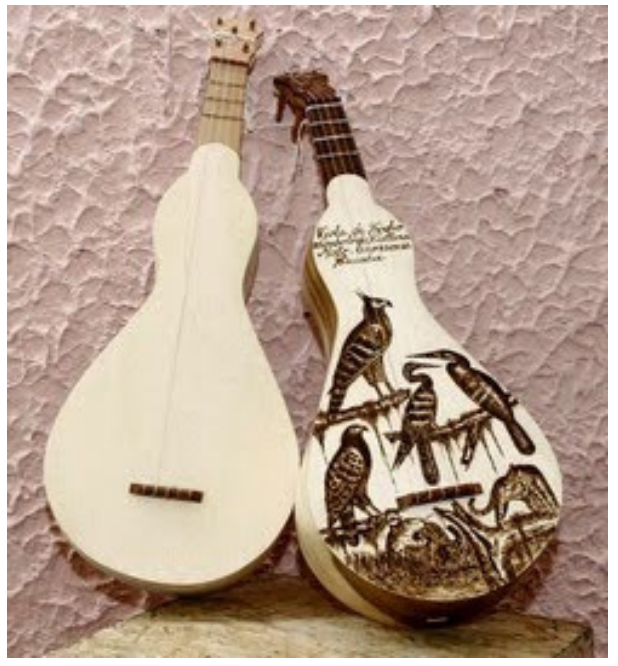

Viola de Cocho 


\section{Viola de Buriti}

Pouco se sabe sobre a origem da viola de buriti ou viola de vereda. É um tipo de viola característica das regiões do Tocantins (Jalapão), mas também é encontrada no noroeste de Minas Gerais. É frequentemente utilizado como um instrumento lúdico em brincadeiras infantis. Muito "simples", rústica e extremamente leve, essa viola é fabricada artesanalmente do talo da palma de buriti.

Atualmente, o encordoamento da viola de buriti é feito em nylon, com quatro ordens. $\bigcirc$ corpo da viola apresenta um formato retangular, composto por três peças. A peça central é mais alongada, formando o braço da viola, sem trastes. Nela existe uma pequena abertura formando a boca e o cavalete está posicionado sobre esta peça central.

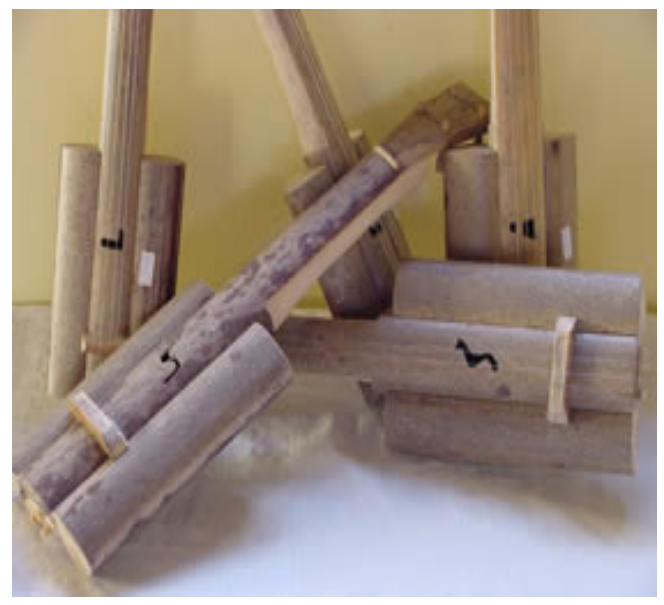

Viola de Buriti

\section{Viola Caiçara}

A viola caiçara é também chamada de viola-de-fandango ou viola branca. Esta viola é encontrada na cidade de Cananéia, litoral sul de São Paulo. Apresenta-se, de forma geral, com seis ou sete cordas dispostas em cinco ordens. As violas caiçaras atuais não diferem das violas antigas, a não ser por uma característica bem peculiar: em 
algumas delas existe um pequeno cravelhal, afixado ao lado da caixa de ressonância, em cima do braço, com apenas uma cravelha. Esta corda é denominada cantadeira. A existência desta corda adicional, reproduzindo a nota mais aguda da afinação, torna-a reentrante, por produzir a nota mais aguda da afinação. Como exemplo de uma das afinações utilizadas podemos citar: [A3 (cantadeira), D2-D1, C2-GI, C3, E3, A2].

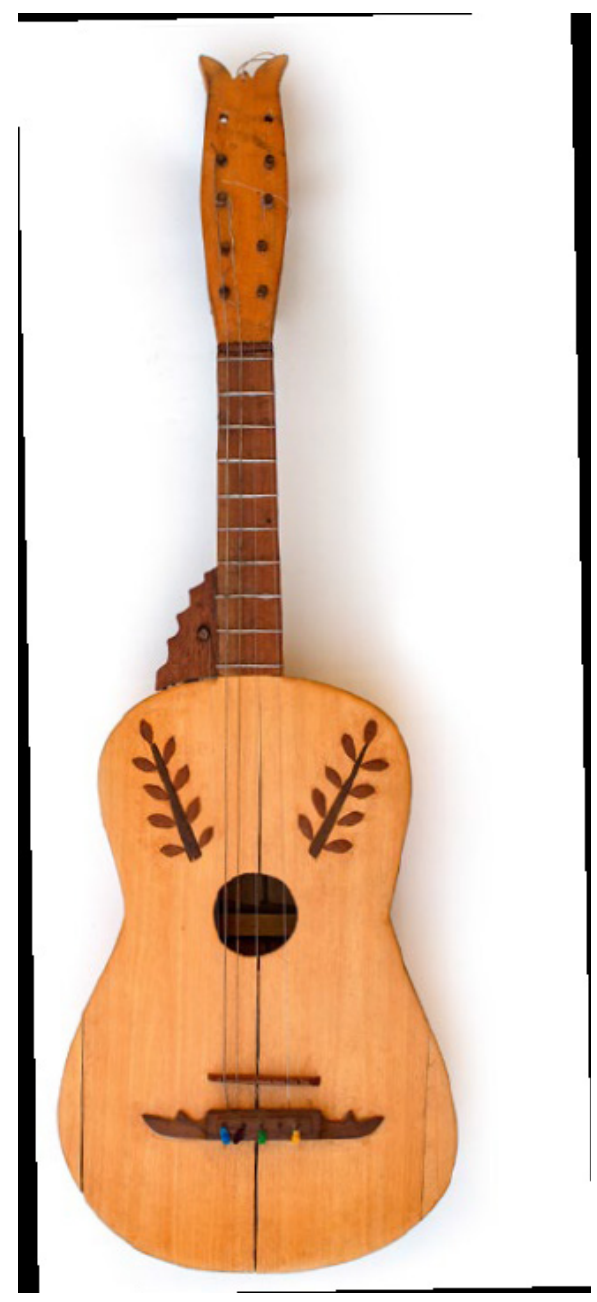

Foto: Viola Caiçara de João Saenger

\section{0}




\section{Viola-machete}

Viola machete ou viola-de-samba, comumente acompanha os sambas chulas é encontrada na região do recôncavo baiano, arma-se com cinco ordens de cordas metálicas duplas sendo os três primeiros pares afinados em uníssono e os outros dois afinados em oitavas.

Uma das afinações utilizadas: [E3-E2, A3-A2, D3-D3, F\#3-F\#3, B3B3.] (FUNARTE, 2019, P. 13).

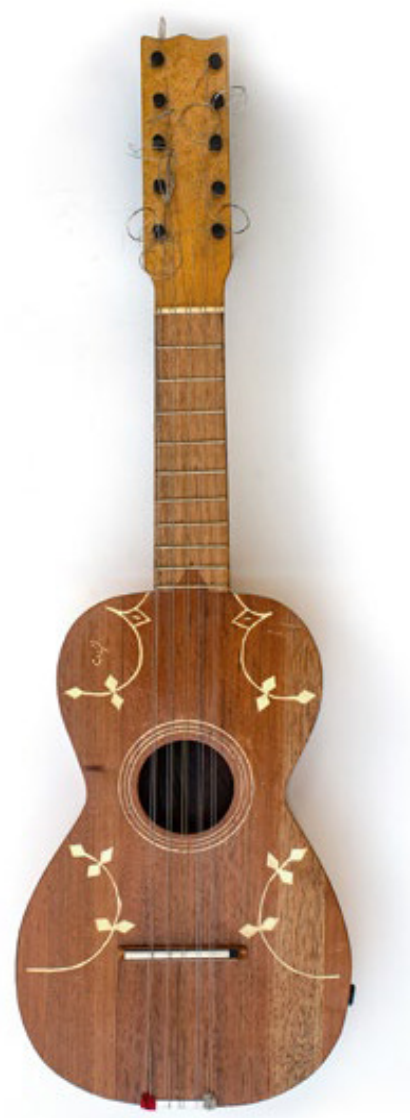

Foto: Viola Machete de João Saenger

\section{1}

REV. TULHA, RIBEIRÃO PRETO, v. 6, n. 1, pp. 9-35, jan.-jun. 2020 


\section{Os termos "viola" e "viola brasileira"}

O termo é considerado a unidade mínima da terminologia (ISO 704; ISO 1087-1). Mais especificamente, o termo é uma designação que corresponde a um conceito em uma linguagem de especialidade. É um signo linguístico que difere da palavra, unidade da língua geral, por ser qualificado no interior de um discurso de especialidade.

Na terminologia os conceitos são elaborados por meio de linguagem natural para definir termos do discurso especializado. É considerado como uma das chaves de acesso para o mundo das ciências e das técnicas. Constitui, para os especialistas, vocabulário essencial para comunicação eficaz, por meio dela se tem contato inicial com a linguagem de determinada área do saber para transformá-la em conhecimento.

Terminologia com "T" maiúsculo, campo (área) de estudo que trata dos termos utilizados em situações de comunicação técnico-científica. Exemplo: estudo dos termos de arte (procedimental). Terminologia com " $t$ " minúsculo é conjunto de palavras comuns a uma área científica, técnica ou tecnológica (conjunto de termos). Exemplo: a terminologia das artes; a terminologia da química, etc (BARROS, 2004).

A Terminologia é tão antiga quanto à linguagem humana. Desde os tempos remotos, o homem dá nome às coisas, aos animais, às plantas, às fontes naturais de alimentação e sobrevivência, aos instrumentos de trabalho, aos artefatos para defesa pessoal, às peças do vestuário, em suma, a tudo que the está à volta. Em um mundo multilíngue e no contato entre civilizações, sente-se a necessidade de compreender o universo nomeado por outros homens e começam, então, a compilar palavras, relacionar conteúdos, identificar equivalentes. Nascem os dicionários bilingues e obras similares nos quais os termos [...] ocupam lugar de destaque (BARROS, 2004, p. 28).

- termo viola designa uma série de instrumentos de cordas friccionadas e dedilhadas com tamanhos, formas, encordoamentos e modos de tocar distintos. As múltiplas maneiras de nomear a viola tem 
relação com a questão geográfica e o contexto cultural ao qual ela é inserida.

No Brasil, com a chegada dos portugueses, pressupõe-se que a viola tenha sido o primeiro instrumento de cordas dedilhadas a chegar em solo brasileiro, pela praticidade e facilidade de construção e de transportá-lo.

A viola, também, era facilmente transportada e podia ser fabricada em qualquer lugar, mesmo que de forma rudimentar. As cordas podiam ser feitas de tripa de animais ou de fibras de plantas. Haviam ainda as cordas de arame (de metal, lisas ou encapadas) que passaram a ser utilizadas no final do século XVIII e eram disponibilizadas em carretéis facilmente armazenados e transportados. Conhecemos exemplares da viola de cinco ordens de cordas dedilhadas no Brasil desde o final do século XIX (CORRÊA, 2019, p. 9).

A falta de definição e classificação do termo viola dificulta a sua identificação nos registros encontrados, justamente por não relatarem com exatidão qual era a viola em questão. Temos outros instrumentos de cordas friccionadas que não são da familia das cordas dedilhadas que recebem o nome de viola, como por exemplo, a viola de arco comumente tocada em orquestra, a viola da gamba, a viola da braccio.

Oriundas de Portugal, a viola está presente no Brasil desde os tempos coloniais. Apesar de bastante citada na documentação deste período, não sabemos ao certo a qual tipo de viola os autores se referiam, pois o instrumento não era descrito em seus pormenores. Da mesma forma, relatos de viajantes estrangeiros do século XIX pelo Brasil citam 0 instrumento viola, mas sem precisar detalhes de modo a permitir uma identificação de suas características, mesmo que parcial. $\bigcirc$ que ocorre é que a palavra viola por si só refere-se a vários tipos de instrumentos, desde os cordofones de cordas dedilhadas aos de cordas friccionadas, dificultando um maior entendimento de qual instrumento estão se referindo. Embora na documentação do período colonial, assim como nos relatos de viajantes do século XIX, não encontremos referências descritivas dos 
instrumentos designados por "viola", é frequente nos relatos verificar a sua presença como instrumento acompanhador de cantos sacros e profanos. Tal fato nos sugere a ocorrência da viola de cordas dedilhadas, pois esta permite a construção de acordes para o acompanhamento (CORRÊA, 2019, p. 9).

A viola que chegou ao Brasil com os portugueses certamente desembarcou com uma bagagem cultural, suas características físicas e modos de afinar e tocar. Na mão do brasileiro, no movimento bandeirante, foi constantemente sofrendo alterações. As violas brasileiras atualmente têm especialidades físicas muito diferentes das "violas antigas" e inclusive da viola de Portugal presentemente.

Com base nestes exemplares, pode-se constatar que no Brasil, até meados do século XX, a viola de cinco ordens de cordas dedilhadas manteve a estrutura básica da viola em Portugal, seguindo um mesmo padrão, ou seja: cravelhas de madeira, cavalete estilizado, e trasteira, escala ou regra madeira onde se fixam os trastes, no mesmo nivel do tampo ou testo sonoro do instrumento. Há uma referência material importante que documenta a presença da viola de cinco ordens dedilhadas em Portugal no século XVI. Assim eram as violas brasileiras mais difundidas, encontradas entre os violeiros tradicionais de então. A maioria possuía apenas dez trastes, mas algumas apresentavam dois trastes a mais, fixados no próprio tampo. A estas "violas antigas" se contrapõem as "violas modernas" que foram incorporando, a partir de meados do século XX, inovações da luteria moderna como, por exemplo, tarraxas de metal e a trasteira indo até a boca do instrumento com um ressalto sobre o tampo escala sobreposta. Outra modificação significativa foi a adoção de doze trastes até o bojo do instrumento, em vez dos dez trastes das violas antigas, e mais alguns trastes, já na parte sobreposta ao tampo, até a boca do instrumento (CORRÊA, 2019, p. 9).

\section{4}

REV. TULHA, RIBEIRÃO PRETO, v. 6, n. 1, pp. 9-35, jan.-jun. 2020 
Podemos dividir as violas brasileiras em dois grupos: as violas que se encordoam com cordas singelas, duplas ou triplas e de metal e as violas que se encordoam com cordas de náilon simples como e o caso da viola de cocho e buriti. Corrêa ressalta que:

As violas de cordas dedilhadas brasileiras da atualidade possuem, em sua maioria, cinco ordens de cordas metálicas. Temos ainda dois outros tipos de violas no Brasil que não se encordoam com arame. A viola-de-cocho (de cinco ordens), encontrada nas práticas musicais de alguns municípios dos estados de Mato Grosso e Mato Grosso do Sul encordoadas com cordas de náilon ou tripas de animais; e a viola-de-buriti (de quatro ou de cinco ordens), encontrada, da mesma forma, em localidades da região centro-norte, também encordoadas com náilon. É importante destacar ainda, que, no Brasil, diferentes instrumentos podem ser designados por viola, a saber: viola (violão), viola (cinco ordens de cordas, singelas, duplas ou triplas), viola-de-doze-cordas (seis ordens de cordas duplas), viola-de-doze-cordas (cinco ordens de cordas sendo três ordens duplas e duas triplas), viola (de arco) e viola (violão-de-7-cordas) (CORRÊA, 2019, p. 9).

$\bigcirc$ termo viola brasileira sem seus termos específicos gera um problema que dificulta a classificação e identificação de cada um desses instrumentos, assim como na compreensão das suas particularidades e suas origens.

$\bigcirc$ fato desta variedade de instrumentos, diferentes em estruturas, detalhes e inserção cultural, ser designada genericamente por viola gera confusões e dificulta 0 trabalho de classificação. É um conjunto que não fecha e não deve fechar nunca, pelo dinamismo próprio da cultura. No entanto, buscar uma certa ordem traz benefícios para se ter maior precisão na identificação de cada um dos instrumentos e se compreender melhor suas particularidades. É neste sentido que avançamos tendo como foco as violas brasileiras de cinco ordens de cordas dedilhadas. Tratase de um conjunto de instrumentos de tradição oral onde o aprendizado e o repasse de repertório se dava por observação/imitação e cujo processo de escolarização e de escrita musical é bem recente (CORRÊA, 2019, p. 9).

\section{5}

REV. TULHA, RIBEIRÃO PRETO, v. 6, n. 1, pp. 9-35, jan.-jun. 2020 
É fato que o termo viola caipira se consagrou por meio do mercado fonográfico com Cornélio Pires, o principal expoente a bancar as primeiras gravações de inúmeras duplas caipiras do interior paulista. Fato este fez com que o instrumento se consolidasse e a produção musical da viola caipira girasse em torno deste segmento.

Um ou outro instrumentista e compositor seguiu pela linha erudita, como por exemplo, Ascendino Theodoro Nogueira. Ascendino compôs peças para viola brasileira, termo utilizado em substituição à viola caipira, para uma aceitação maior do mercado de música erudita. Este artifício não alcançou a projeção que teve a música caipira com as duplas e os programas de rádio da época.

No entanto, o uso do termo viola caipira ${ }^{3}$, atualmente, não corresponde a produção musical nos dias de hoje, os músicos que tocam viola não se restringem a produzir somente música caipira. A viola está presente em todo tipo de gênero musical (pop, rock, samba, choro, música regional, popular ou erudito, internacional, etc.). A maioria dos violeiros ${ }^{4}$ (podemos citar: Ivan Vilela, Neymar Dias, João Paulo Amaral, Reinaldo Honório, Arnaldo Freitas e Vinícius Muniz) tem utilizado o termo "viola brasileira" por entenderem ser o mais adequado à produção musical de viola na atualidade.

Um fato evidente é que as instituições de ensino superior pública e privada ofertam em sua grade curricular um bacharelado em viola (instrumento de cordas dedilhadas) referindo se ao mesmo instrumento utilizando-se de termos diferentes. A Universidade de São Paulo campus capital e no interior Ribeirão Preto possui um curso para viola, porém na capital é denominada "viola brasileira" e em Ribeirão Preto "viola caipira”. A Faculdade Cantareira, uma instituição particular, oferta um curso de bacharel em "viola caipira" ministrada pelo professor João Paulo Amaral.

3 Roberto Corrêa, Ricardo Vignini e Índio cachoeira denominam o instrumento como viola caipira em seus discos.

4 Dentre os violeiros citados, todos denominam o instrumento como viola brasileira vide os discos gravados nas referências. Outro fato a destacar é o curso de viola brasileira ofertado pela Universidade de São Paulo (USP) do Campus São Paulo ministrado pelo professor Gustavo Costa, curiosamente o curso da Universidade de São Paulo (USP) do Campus Ribeirão Preto é denominado viola caipira.

\section{6}

REV. TULHA, RIBEIRÃO PRETO, v. 6, n. 1, pp. 9-35, jan.-jun. 2020 
Porém, o termo viola brasileira gera uma confusão no sentido etimológico da palavra. Para a ciência da informação soa como um termo geral para definir as diversas violas espalhadas pelo Brasil. Viola brasileira é a designação genérica de uma categoria diversificada dos cordofones de mão com caixa de ressonância (a maioria em forma de 8), braço e ordens de cordas simples, duplas e as vezes triplas dependendo da região.

Com o estudo da ciência da informação voltado à terminologia pretendemos aqui classificar os termos relacionados a viola.

\title{
Para Maria Teresa Cabré5:
}

\begin{abstract}
A terminologia, como indicamos, é o fator privilegiado, embora não seja o único, de representação do conhecimento especializado. $\bigcirc$ grau de especialização de textos especializados varia sua densidade terminológica: quanto maior o nível de especialização, maior a espessura da terminologia. Portanto, se as unidades terminológicas são o modo privilegiado de expressão do conhecimento especializado, podemos dizer que sua primeira função é representar o referido conhecimento. Cada unidade terminológica corresponde a um nó cognitivo dentro de um campo de especialidade, e o conjunto dos referidos nós conectados por relações específicas (causa-efeito, todo as parte, contiguidade, anterioridade-posterioridade etc.) constitui a representação conceitual da referida especialidade. Nesse caso, não há dúvida de que a terminologia é uma maneira de representar a realidade especializada (CABRÉ, 1999, p. 238, tradução nossa).
\end{abstract}

5 La terminología, como hemos indicado, es el factor privilegiado, aunque no el único, de representacion del conocimiento especializado. el grado de especializacion de los textos de especialidad hace variar la densidad terminológica de los mismos: a mayor nivel de especializacion, mayor espesor terminologico. Por ello, si las unidades terminologicas son el modo privilegiado de expresión del conocimiento especializado, podemos decir que su primeira función es la de representar dicho conocimiento. Cada unidad terminologica corresponde a un nudo cognitivo dentro de un campo de especialidad, y el conjunto de dichos nudos conectados por relaciones específicas (causa-efecto, todo-parte, contiguidad, anterioridad-posterioridad, etc.) constituye la representación conceptual de dicha especialidad. Si ello es asi no cabe duda de que la terminologia es una forma de representar la realidad especializada. 
A terminologia nasce de uma necessidade de unificar, classificar e comunicar universalmente sobre diversos domínios em usos profissionais.

A falta de muitas décadas de reflexão sobre a coerência da teoria e suas aplicações são explicadas pelas próprias características da origem da teoria terminológica. Com efeito, as primeiras atividades relacionadas à padronização da terminologia surgem dos cientistas que precisam estabelecer formas únicas de comunicação para seus usos profissionais. Surgem, assim, as nomenclaturas nas ciências naturais e experimentais, e formas padronizadas. Logo depois, as necessidades das trocas comerciais causadas pelo início da industrialização levam à elaboração de regulamentos de produção, principalmente para uso interno, para racionalizar sua produção e, em seguida, para escopo mais geral para facilitar as relações de troca. Esses regulamentos são o precedente mais claro do que as regras serão mais tarde. A partir de então, a evidencia de que um regulamento isolado sobre produtos se torne inoperante se não for acompanhado por um regulamento sobre a linguagem que os designa. Portanto, a padronização industrial é revelada como uma atividade intimamente ligada à terminologia. A revolução industrial do século XIX, que definitivamente promove a cooperação internacional, levanta explicitamente a necessidade de unificar alguns sistemas de produção, medidas, pesos e outros aspectos sujeitos a troca (e, com eles, também a terminologia), confirmando a crescente importância da normalização terminológica como prática que permite reduzir diferenças e favorecer a comunicação de base econômica. Parece óbvio, então, que se a comunicação internacional exigisse a normalização de objetos e atividades, a normalização de denominações, no sentido de reduzir possiveis variedades para um, o padrão, era totalmente inevitável. Até agora, a padronização da terminologia tinha uma estrutura única: a comunicação Internacional padronizado principalmente para questões industriais (CABRÉ, 1999, p. 243).

\section{8}

REV. TULHA, RIBEIRÃO PRETO, v. 6, n. 1, pp. 9-35, jan.-jun. 2020 


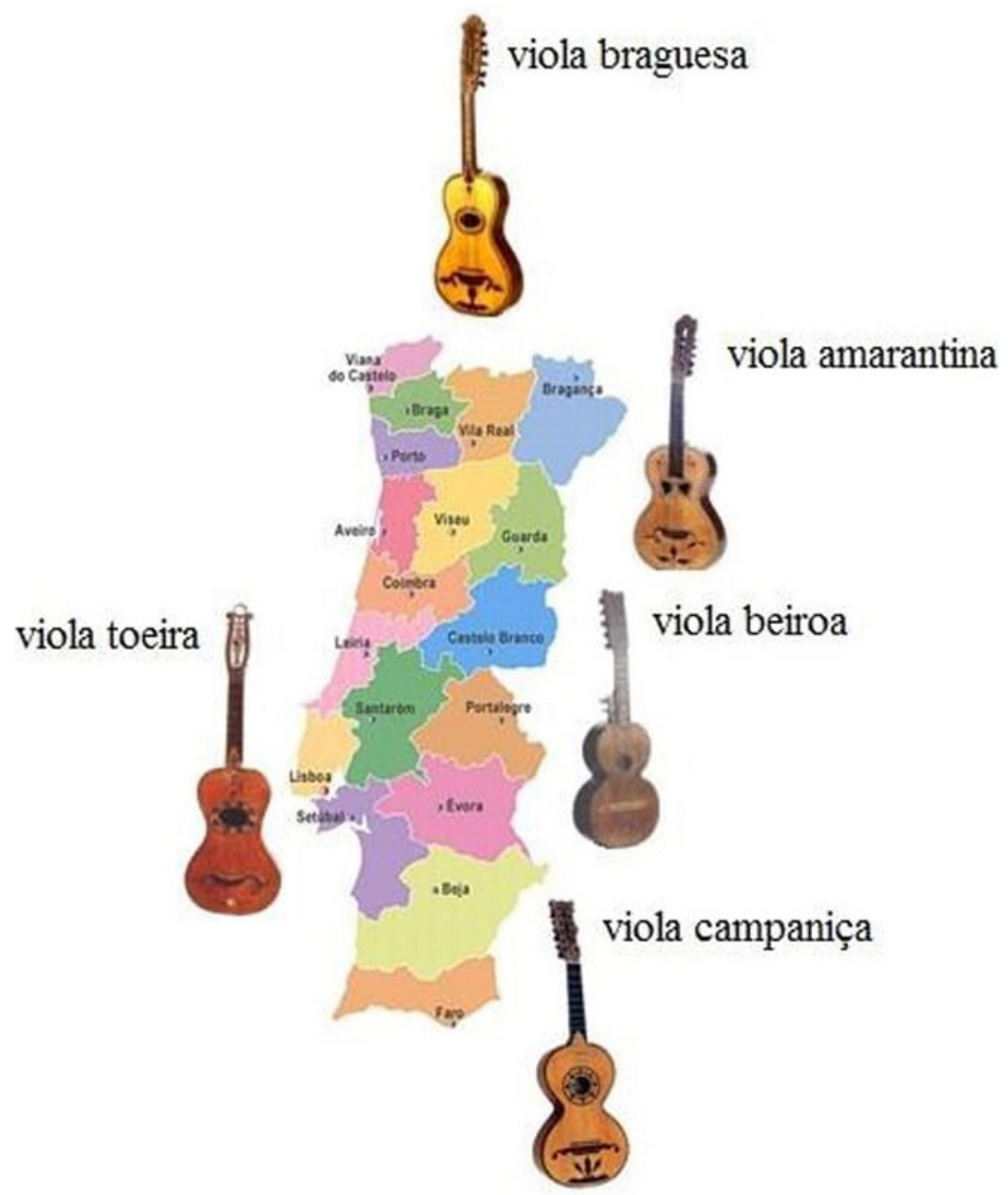

Imagens da dissertação de mestrado do Fábio de Souza Miranda (2016) 


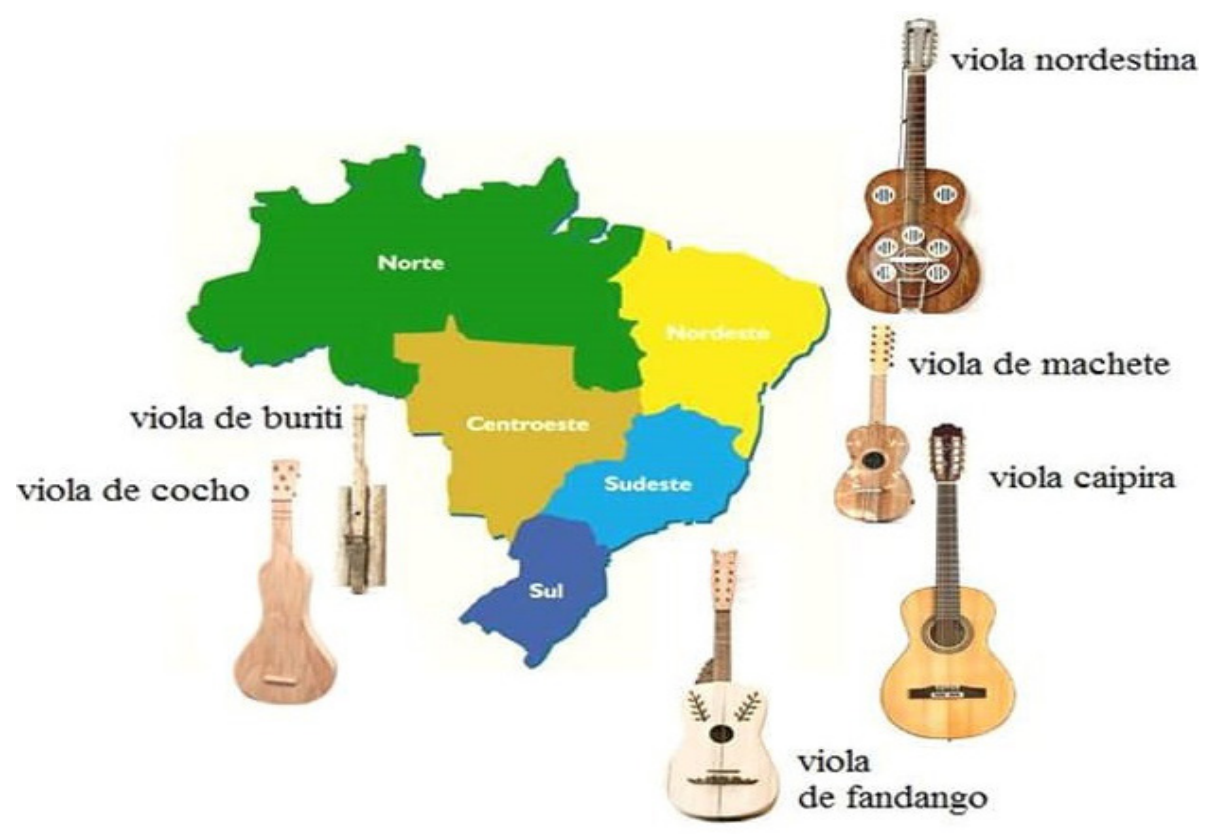

Imagens da dissertação de mestrado do Fábio de Souza Miranda (2016)

Podemos observar que as violas brasileiras se alocaram por regiões como as violas portuguesas, outro fator notório é que há muitas semelhanças de construção em ambas as violas, exceto as violas de cocho e buriti, que não se sabe ao certo quais influências herdaram.

Podemos notar que as violas brasileiras recebem os seus nomes de acordo com o material que ela é produzida, associando à região ou à função que ela exerce dentro de uma comunidade local.

Viola: Instrumento; Caipira: Propriedade;

Termo: Viola Caipira; pois um termo pode ser formado por mais de uma palavra.

Viola (Termo Genérico - TC);

Viola Caipira (Termo Específico - TE), pois é um tipo de Viola. 
A relação entre o TC viola e o TE viola caipira é hierárquica do tipo gênero espécie; pois viola caipira é uma espécie de viola.

Seria termo relacionado se o termo formasse uma relação associativa com o Termo Viola.

Num tesauro ${ }^{6}$ temos três tipos de relações:

Hierárquicas [1] Todo, parte ou Partitiva; [2] Equivalente e; [3] Associativa.

Viola caipira e viola brasileira, viola caipira é brasileira, mas nem toda viola brasileira é caipira.

\section{Conclusão}

A viola caipira tem, em sua história, a riqueza e diversidade de formatos físicos, afinações, maneiras de se tocar, que estão relacionadas a eventos religiosos, manifestações populares do povo e rodas de viola (dança do cururu, catira e São Gonçalo, as folias de reis, procissões do divino, as duplas caipiras, entre outras). Devido ao seu reenraizamento no Brasil, atualmente, desperta o interesse de compositores e instrumentistas, sendo utilizada em outros gêneros musicais como roda de choro, samba, forró, rock, frevo e salas de concerto.

O termo viola brasileira tem sido muito utilizado em substituição ao termo viola caipira pelos compositores, instrumentistas e professores de viola de cordas dedilhadas. Como cita Roberto Corrêa, isso gera um problema de classificação e organização desses instrumentos, pois a viola caipira tem características físicas, linguagens, contexto social e geográfico diferentes de outras violas que existem pelo Brasil.

Então, como podemos chamar de viola brasileira a viola caipira conhecida popularmente no Brasil? E as demais violas como as violas de buriti, de cocho, caiçara, machete, cabaça, não são brasileiras? Em conversa com alguns compositores e violeiros, a justificativa é a ascensão da viola caipira em transitar em diversos gêneros musicais,

6 Grande acervo de palavras de um âmbito do conhecimento que faz a descrição clara de seus conceitos. 
não se restringindo somente a música caipira, pois o termo "viola caipira" limita ou sugere que o instrumento é capaz somente de produzir música dentro deste segmento. Com a expansão técnica e interpretativa que a viola alcançou nas últimas décadas o termo "viola caipira" na opinião desses violeiros, não corresponde mais à suas produções.

Não está no escopo deste trabalho definir alternativas ou soluções, o intuito é discutir as possibilidades de classificação e organização com relação ao termo viola. Não pretendemos aqui definir novos termos, mas sim fazermos uma reflexão sobre os caminhos terminológicos para facilitar a comunicação no entorno da viola. Por fim, apenas saberemos sobre a eficácia do termo viola brasileira com a eventual consagração de seu uso nas próximas décadas.

\section{Referências}

AMARAL, João Paulo. Viola caipira: arranjos instrumentais de músicas tradicionais para solo, duo e trio de violas. Campinas, SP; Edição do autor, 2008.

AMARAL, João Paulo. Viola Brasileira: João Paulo Amaral Trio. Tratore, 2010. Disponivel em: https://tratore.com.br/um_cd.php?id=1767. Acesso em: 04. Abril. 20.

AMARAL, João Paulo. Viola caipira: Disciplina. Faculdade Cantareira, 2020. Disponivel em: http://cantareira.br/curso/musicabacharelado-mais-informacoes/\# 1538755996284 -cdb8 19cc-6575. Acesso em: 05. Abril. 20.

BARROS, L. A. Curso básico de terminologia. São Paulo: Edusp, 2004.

CABRÉ, M. T. Terminología Y documentación. In: La terminologia: representación y comunicación: elementos para una teoría de base comunicativa y otros artículos. Barcelona: ULA/Universitat Pompeu Fabra, 1999. p. 231 -247.

CACHOEIRA, Índio. Solos de Viola Caipira: Índio Cachoeira. Tratore, 2007. Disponivel em: https://www.tratore.com.br/um_cd.php?id=940. Acesso em 05. Abril. 20. 
CORRÊA, Roberto Nunes. A arte de pontear viola. 2. ed. Brasilia: Viola Corrêa, 2002.

CORRÊA, Roberto Nunes. Composições para viola caipira. I. ed. Brasilia: Viola Corrêa, 2004.

CORREÁA, Roberto Nunes. Viola caipira: das práticas populares à escritura da arte. 2014. Tese (Doutorado em Musicologia) - Escola de Comunicação e Artes da Universidade de São Paulo, São Paulo.

CORRÊA, Roberto Nunes. Song book online: As violas do Brasil. Funarte, 2018. Disponivel em: http://www.funarte.gov.br/partiturasbrasileiras-online/Acesso em 15 de dez. 2019.

COSTA, Gustavo Silveira. Viola Caipira I: Disciplina. USP digital, 2020. Disponivel em: https://uspdigital.usp.br/jupiterweb/ obterDisciplina? sgldis=597 1339 Everdis=2. Acesso em: 05. Abril. 20.

DIAS, Neymar. Feels Bach: Viola Brasileira Solo. Tratore, 2017. Disponivel em: https://tratore.com.br/um_cd.php?id=10610. Acesso em: 04. Abril. 20.

FREITAS, Arnaldo. Curso online Viola Brasileira. Arnaldo Freitas, 2019. Disponivel em: https://www.sympla.com.br/viola-brasileira-aovivo_682045. Acesso em: 04. Abril. 20.

ISO 704. Terminology work - principles and methods.

ISO 1087. Terminology work - vocabulary.

MIRANDA, Fábio de Souza Roda de Viola: Jogos musicais no ensino coletivo da viola caipira, São Paulo, 2016. (Dissertação de mestrado) - Programa de Pós Graduação em música Escola de Comunicação e Artes, Universidade de São Paulo, São Paulo.

MUNIZ, Vinícius. J.S.Bach Viola Brasileira- Prefácio. Youtube, 17 mar. 2017. Disponivel em https://www.youtube.com/watch? $v=8 \mathrm{KaktmxwOHE}$. Acesso em: 04 abril. 20.

PETENÁ, César. A Viola brasileira na sala de concerto: Os sete prelúdios de Theodoro Nogueira. 2017. Trabalho de Conclusão de 
Curso (Bacharelado em Música) - Faculdade Integral Cantareira, São Paulo.

SACER, J. Prólogo: la terminología, ponte entre varios mundos. In: CABRÉ, M. T. La terminología: teoría, metodología, aplicaciones. Barcelona: Ed.Antártida; Empúries, 1993. p. 11-17.

TOLEDO, Reinaldo. 1 I Estudos para viola brasileira. Tratore, 2018. Disponivel em: https://www.tratore.com.br/um_cd.php?id=13104. Acesso em: 04. Abril. 20.

VICNINI, Ricardo. Viola Caipira duas gerações. Tratore, 2014. Disponivel em: https://www.tratore.com.br/um_cd.php?id=6342. Acesso em: 05. Abril. 20.

VILELA, Ivan. Viola Brasileira I: Disciplina. USP digital, 2017. Disponivel em: https://uspdigital.usp.br/jupiterweb/ obterDisciplina? sgldis=CMU073 | \&verdis=1. Acesso em: 04 abril. 20.

VILELA, Ivan. Cantando a própria história. Tese (Doutorado em Psicologia Social) - Departamento de Psicologia social da Universidade de São Paulo, São Paulo, 2011.

\section{Sobre o autor}

Possui graduação em música pela Faculdade Santa Marcelina. Formado em violão erudito pela Universidade Livre de Música (ULM) e viola caipira na Escola de Música do Estado de São Paulo (EMESP), com o mestre João Paulo Amaral. Mestrando em música e educação: processos de criação, ensino e aprendizagem pela Universidade de São Paulo (USP) sob. Orientação do professor livre docente Marcos Câmara de Castro. Desde 2013 tem se dedicado ao ensino da música no âmbito coletivo, em escolas de ensino regular estadual e instituições particulares. Atualmente ministra aulas coletivas de violão na Prefeitura Municipal Embu-Guaçu, de viola caipira na Prefeitura Municipal de Embu das Artes, na Prefeitura Municipal de São Bernardo do Campo, Prefeitura 
Municipal de Franco da Rocha, no Serviço Social do Comércio (SESC) de Campinas, Campo Limpo e Guarulhos, além de aulas particulares. Participou de oficinas de formação com grandes educadores musicais de métodos ativos nacionais e internacionais. Tem se apresentado em várias cidades de São Paulo e interior com trabalhos ao lado do violeiro César Petená, além de integrar a Orquestra Filarmônica de Violas de Campinas.

Recebido em 13/02/2020

Aprovado em 06/04/2020 